$\$=1$

\title{
Platelet rich fibrin in dentistry: A review of literature
}

\author{
Vishnu Ravi Kumar*, Gayathri Gangadharan \\ Manipal College of Dental Sciences (MCODS),Manipal, Karnataka, India \\ *Corresponding author E-mail: vishnu.ravikumar1@gmail.com
}

\begin{abstract}
The aim of any invasive procedure is the complete eradication and elimination of the infection and associated necrotic tissue followed by repair and regeneration of the affected tissue. In order to achieve this goal various biological products have been introduced, among which are present the platelet concentrates. Platelet concentrates with their higher concentration of platelets has been used in the field of medicine since the 1990s in the form of the first-generation concentrates-Platelet Rich Plasma, and the second generation concentrated Platelet Rich Fibrin. Choukroun's Platelet Rich Fibrin is one such material, which is used by itself and also as an adjunct with grafts. It has been successful as it delivers high doses of growth factors and has anti-inflammatory properties. They have been shown to be of great promise in the field of dentistry, ranging from implantology; Sinuses lift procedures, treating of endodontic and periodontal lesions to regeneration of necrotic pulp. This novel technique has the potential to revolutionize the treatment mode in dentistry and help with reducing patient morbidity. We will be further looking into the specification and implications of this material in this review.
\end{abstract}

Keywords: Healing; Growth Factors; Platelet Concentrates; Platelet Rich Fibrin; Regeneration.

\section{Introduction}

With the recent advances in tissue engineering, which is the study of the growth of new connective tissues, or organs, from cells and a collagenous scaffold to produce a fully functional organ for implantation back into the donor host, there has been a vast improvement in the healing response of tissues (Bianco P etal.2001) Oral lesions, both soft and hard tissue, lead to bony defects that increase the morbidity (Albanese et al. 2013). So as to reduce the healing time of such lesions, a lot of research has been going on in the search for an ideal scaffold, a "biofuel" of sorts who can help in the repair and reconstruction of these defects. As a result, platelet concentrates were found to enhance the healing response of the body, with Platelet-Rich Fibrin showing promising results (Khiste et al. 2013). Advancement in this field has helped to create a way to use the patient's own tissue to repair and regenerate various bony and soft-tissue lesions (Zaky et al. 2009).

Platelet-Rich Fibrin (PRF) consists of a strictly autologous fibrin matrix rich in platelets, leukocyte cytokines, and various growth factors. This concept was described in France by Choukroun in 2001(Choukroun et al. 2006), it is a second-generation platelet concentrate used for its ability to enhance tissue repair and regeneration. It was introduced as a replacement for the Platelet-Rich Plasma (PRP), also known as the first-generation platelet derivatives, as it is simple and safe compared to PRP (Choukroun et al. 2006, Chowdhury et al. 2013)

\section{Platelet concentrates}

Platelet concentrates have been in use for the past 30 years, and its use stems from the ability of the fibrin glue to enhance healing. Fibrin, the activated form of the plasmatic molecule fibrinogen, plays a determining role in the platelet aggregation during hemo stasis. Fibrin glue is a human-derived tissue adhesive that can be used for hemostasis and healing of tissues, and is derived from two components, the first containing human fibrinogen and coagulation factors IX and varying amounts of plasma proteins, and the second component containing the thrombin (Burnouf et al. 2008, Choukroun et al. 2006)

The final step of the blood coagulation cascade is mimicked in the process of preparation of fibrin glue during the mixing of fibrinogen and thrombin. This process results in the formation of a fibrin clot of varying rigidity that acts as a fluid-tight sealing agent who helps to stop the bleeding. Fibrin glue is donor-derived, and because of the low fibrinogen concentration, its stability and strength was also low. Also Albrektsson et al. (1982) reported that the fibrin sealant had a negative effect on bone healing (Guéhennec et al. 2004, Inchingolo et al. 2010).Later, Later, the platelets from the peripheral blood was identified to be a better autologous source of growth factors which, when used with the growth factors, provided predictable outcomes.

\section{Platelet rich plasma}

The Platelet-Rich Plasma (PRP), an autologous product concentrating a large number of platelets in a small volume, was found to be an easily accessible source of growth factors to enhance the bone and soft-tissue healing. It was derived by methods that enabled the concentration of autologous platelets in the fibrin clot; the fibrin clots being the focus of initiating the healing and repair. It differs from fibrin glue and other non-platelet tissue adhesives because of the presence of platelets, which has a unique ability to promote wound healing and enhance osteogenesis. PRP accelerates endothelial, epithelial, and other tissue regeneration, stimulates angiogenesis, supplements collagen synthesis, promotes softtissue healing, and enhances the hemostatic response to injury. And since it is an autologous blood product, it has no risk of transmitting infectious disease (Albanese et al. 2013). 
PRP has an extremely broad range of clinical healing applications in head and neck surgery, otolaryngology, cardiovascular surgery, burns and wound healing, oral and maxillofacial surgery, cosmetic surgery, and periodontics (Marx ER 1999).

But, there were potential risks associated with the use of PRP. During the preparation of the PRP, after the blood is collected, it is immediately mixed with an anticoagulant so as to prevent clotting, and thus to neutralize this, bovine thrombin is added to bring about the coagulation. Thus, the use of PRP may lead to the development of antibodies to the factors V, XI and thrombin, resulting in the risk of occurrence of life-threatening coagulopathies. Bovine-thrombin preparations containing factor $\mathrm{V}$ stimulate the immune system when challenged with a foreign protein (Raja $e t$ al. 2008).

\section{Classification of platelet concentrates}

As per the current classification (2009), platelet concentrates can be generally classified into four groups (Fig: 1) based on the presence of leucocytes and fibrin architecture (Ehrenfest et al. 2010, Ehrenfest et al. 2014):

1) Pure PRP/Leucocyte-poor PRP: Absence of Leucocytes and low density of fibrin network after activation. Used in two forms - liquid solution or activated gel.

2) Leucocyte and platelet-rich plasma: Presence of Leucocytes and low-density fibrin network after activation. Also used in two forms - liquid solution or activated gel.

3) Pure platelet-rich fibrin PPRF/Leucocyte-poor PRF: Without leucocytes but with high-density fibrin network. Used in strongly activated gel form.

4) Leucocyte and Platelet-Rich Fibrin: With leucocytes but with high-density fibrin network. Also used in strongly activated gel form.

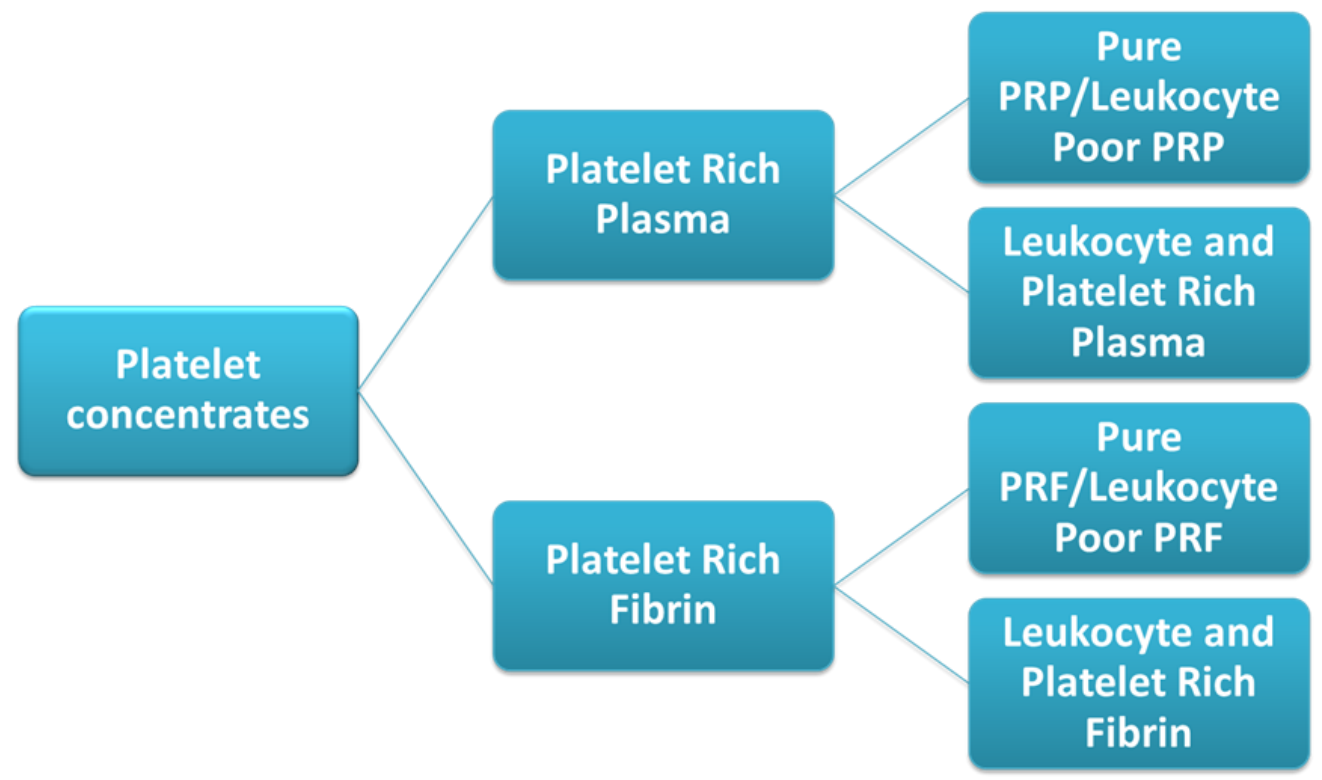

Fig. 1: The Classification of Platelet Concentrates

\section{Preparation of PRF}

One of the advantages of PRF over PRP is the inexpensive and easy protocol for the collection of the patient's blood along with the disuse of the Bovine thrombin and anticoagulants that are usually associated with the use of the PRP in surgical procedures (Raja et al. 2008).

The process involves the collection of $10 \mathrm{ml}$ of venous blood that is collected in a glass test tube. This is immediately followed by the centrifugation process, 3000rpm for 10 minutes. If not immediately centrifuged, diffuse polymerization of fibrin occurs, which results in a clot of reduced quantity and quality (Kobayashi et al. 2012).

After the processing of PRF, the sample of blood in the test tube is allowed to settle and in the process separates into three layers:

The acellular plasma, or platelet-poor plasma (PPP) that is the topmost straw-colored layer, as the name suggests, is lacking in platelet cells.

This is followed by the PRF Clot that is rich in fibrin and has the growth factors and cytokines embedded in the polymerized structure.

The lower fraction that is red and has the RBC cells.

The blood, when collected and placed in the test tube, undergoes the process of intrinsic coagulation on coming into contact with the glass, thereby separating the blood into the clot and the plas- ma. Hence, speedy blood collection and immediate centrifugation is advised for successful preparation of PRF (Chowdhury et al. 2013).

During centrifugation, the fibrinogen in the plasma fraction combines with the thrombin and forms the PRF region that is found between the acellular plasma and the lower-packed RBC-rich fraction.

The superficial acellular fraction is removed, and the middle PRF fraction is then collected along with the attached RBCs from the test tube using pliers. The fibrin clot is placed on a sterile surface, and the RBCs are gently scraped off (Choukroun et al. 2006).

The PRF Box is a device which is used for producing PRF membranes of uniform thickness in less than a minute. The compression procedure is performed with a slow gentle and homogenous pressure, and the final membrane is always wet and soaked homogenously with the serum. There is no significant loss of extrinsic incorporated platelet growth factors and has no influence on the intrinsic incorporated growth factor (Ehrenfest 2010). Also, it helps in obtaining the serum exudate which is rich in fibronectin and vitronectin (Ehrenfest et al. 2009). 


\section{Architecture and composition of the PRF membrane}

Both, Fibronectin and Vitronectin are key proteins that play a very important role in the adhesion and migration of the platelets and play a vital role as a key component of the architecture of the fibrin clot. The strong architecture of the fibrin clot formed causes the slow release of the fibronectin over a period of seven days, the fibronectin released initially is the free fibronectin from the exudate and later is replaced by the fibronectin from the PRF membrane. On the other hand, vitronectin is released from the PRF membrane only during the first four hours followed by almost a negligible release over the next seven days (Ehrenfest et al. 2012). Although platelet growth factors play an important role in the biology and functioning of PRF, the fibrin architecture and leukocyte content are two key parameters that have not been looked into in great detail. The fibrin architecture of the platelet derivatives influences its biology (Albrektsson et al. 1982). The PRF clot is obtained through the natural, polymerization process which occurs during centrifugation, and hence it has natural fibrin architecture. It is thought that this natural architecture is responsible for the slow release of growth factors. Such a a slow release has not been observed in PRP as it involves a very rapid and artificial platelet activation and hence has a very light and weak fibrin network (Kobayashi et al. 2012, Simonpieri et al. 2102).

The rate of release of the various growth factors also varies with that of the TGF-b peaking around 5-7 days and that of VEGF and PDGF around 1-2 days and 3-5 days respectively (Ehrenfest $e t$ al. 2012).

In a study by David M. et al, it was observed that after centrifugation and polymerization of the fibrin network, there were hardly any platelets left within the RBC layer or the PPP, hence proving that most of the platelets in the blood sample that was collected were embedded in the fibrin network. It was also observed that more than half of the leukocytes were trapped in PRF membranes.

Table 1: Growth Factors and Their Biological Functions

\begin{tabular}{|c|c|c|}
\hline Growth Factor & Source Cells & Biological Action \\
\hline $\begin{array}{l}\text { Platelet Derived Growth Factor } \\
\text { (PDGF) }\end{array}$ & Platelets, Macrophages & $\begin{array}{l}\text { - Migration and proliferation of mesenchymal stem cells. } \\
\text { - Angiogenic effect on endothelial cells. }\end{array}$ \\
\hline $\begin{array}{l}\text { Transforming Growth Factor } \\
\text { (TGF-b) }\end{array}$ & Platelets, Lymphocytes & $\begin{array}{l}\text { - } \quad \text { Proliferation of osteoblasts } \\
\text { - } \quad \text { Collagen type } 1 \text { production } \\
\text { - } \quad \text { Soven bone formation } \\
\text { Stimulates angiogenesis }\end{array}$ \\
\hline $\begin{array}{l}\text { Insulin like Growth Factor } 1 \\
\text { (IGF-1) }\end{array}$ & Osteoblasts, Macrophages & $\begin{array}{ll}\text { - } & \text { Osteoblast proliferation } \\
\text { - } & \text { Enhances wound healing }\end{array}$ \\
\hline $\begin{array}{l}\text { Fibroblast Growth Factor } \\
\text { (FGF) }\end{array}$ & & $\begin{array}{l}\text { - Osteoblast proliferation } \\
\text { - }\end{array}$ \\
\hline $\begin{array}{l}\text { Vascular Endothelial Growth } \\
\text { Factor (VEGF) }\end{array}$ & Endothelial cells & - Initiates angiogenesis \\
\hline
\end{tabular}

Table 2: Comparison of the Platelet Concentrates

\begin{tabular}{llll}
\hline SAMPLE & $\begin{array}{l}\text { Red Blood Cells } \\
(\text { RBC) }(\%)\end{array}$ & Platelets $(\%)$ & $\begin{array}{l}\text { White Blood Cells } \\
(\text { WBC) }(\%)\end{array}$ \\
\hline Blood Clot & 95 & 5 & 1 \\
Platelet Rich Plasma (PRP) & $\mathbf{4}$ & $\mathbf{9 5}$ & $\mathbf{1}$ \\
Platelet Rich Fibrin (PRF) & $\mathbf{2}$ & $\mathbf{9 7}$ & $\mathbf{1}$ \\
\hline
\end{tabular}

The leucocytes that are found in the membrane not only act as anti-inflammatory cells but also as anti-nociceptive, through the release of chemokines and inti-inflammatory cytokines (IL4,IL10,IL-13) and opioid peptides, and thus help in pain control also (Ehrenfest et al. 2014).

The most important feature of PRF is its ability to accumulate platelets and the slow release of cytokines in the fibrin clot. Histologic analysis revealed that the platelets accumulated at the lower part of the fibrin clot, that is the junction between the fibrin clot and red corpuscles. It was also found that the PRF matrix contains heparin, hyaluronic acid incorporated within the fibrin polymers which helps in supporting cell migration and healing process. The natural polymerization which resulted in three-dimensional fibrin architecture was found to be responsible for the slow release of cytokines over seven days (Ehrenfest et al. 2010).

The first stage of healing is brought about by the slow release of cytokines necessitated by the degranulation of platelets, thereby stimulating the cell migration and proliferation within the fibrin matrix. The fibrin matrix plays a pivotal role in the therapeutic role of PRF. Fibrin, the activated form of fibrinogen, is present in the alpha granules of platelets along with various growth factors. The platelet cytokines were found to be trapped within the fibrin matrix, intimately incorporated into the fibrin polymer molecular structure (intrinsic cytokines). This makes sure that the cytokines are available for a long term. Furthermore, the fibrin matrix consists of weak thrombin concentrations resulting in equilateral junctions. These junctions allow the formation of a fine fibrillary net work which can support cytokine enmeshment and cell migration. Moreover, this organization results in the formation of a flexible, elastic, and very strong PRF matrix (Choukroun et al. 2006).

Of the different materials used in tissue engineering, PRF seems most promising as the fibrin clot acts as a scaffold, thereby providing mechanical support and serving as biologic connectors. It also facilitates cellular migration thereby increasing the vascularization and survival of the graft. The presence of the leucocytes in the fibrin network and the slow release of cytokines results in the selfregulation of inflammatory and infectious process and the continued process of healing (Choukroun et al. 2006, Choukroun et al.

\section{Applications}

Since dentistry deals with teeth and its surrounding structures, hard as well as soft-tissue lesions, PRF has immense use in this field pertaining to its improved healing capacity, and better compatibility with the patient's immune system as it is purely autologous. Following are some of the more common uses of PRF in dentistry:

1) In the treatment of periodontal lesions such as infra bony defects and regenerative procedures, along with Endo-Perio Lesions, PRF can be used as a biological scaffold material. PRF promotes periodontal progenitor cell proliferation and migration in situ compared to GTR membranes. They also have inductive effect on gingival tissue due to the slow release of 
growth factors and cytokines. Since the PRF membrane allows cell migration, they act as a competitive barrier which stimulates the regenerative properties of periosteum by allowing neo angiogenesis and interactions between the gingival flap and alveolar ridges. According to a study by $\mathrm{Qi} \mathrm{Li}$ et al. (2013) it was suggested that the fibrin component of the PRF played a substantial role in the osteo-differentiation as compared to the periodontal progenitors. The study also demonstrated that the PRF augmented the periodontal regeneration in two ways:

a) Promotes the soft tissue healing by modifying the progenitor proliferation and migration.

b) Induction of alveolar bone facilitated by the fibrin mediated effect on RUNX2 expression, osteoblast differentiation and matrix mineralization along with the increase in alkaline phosphatase activity (Shivashankar et al. 2013)

2) Sinus augmentation and in repair of Sinus perforation: Freeze Dried Bone Allograft (FDBA) when used along with PRF is found to accelerate the bone regeneration in cases of sinus augmentation. The healing time was found to reduce considerably. Also, the use of PRF increased the graft volume and reduced the amount of bone harvesting. Although there was no considerable increase in cell proliferation, use of PRF did play a great role in success of the graft by playing a vital role in revascularization of graft by supporting angiogenesis (Choukroun et al.2006). In a study conducted by Marco Tatullo et al. on the effects of PRF in reconstructive surgery of atrophied maxillary bones, it was found that there was a clinical success rate of 87.5 to $100 \%$ in sinus lift by using PRF obtained following Choukroun's protocol (Inchingolo et al. 2010) It was also found that the use of PRF along with PIEZO Surgery reduced the healing time, thereby achieving good primary stability of endosseous implants. The use of PRF allows us to avoid the use of membranes and barriers, and hence reduce the risk of possible exposure to the oral cavity and infection by the oral flora (Toffler et al. 2006).

3) In certain aspects of surgical endodontics such as treatment of periapical lesions and the regeneration of pulp (in a case of tooth with a previously necrotic pulp with an open apex), PRF is used as an ideal scaffold material for the repair and the regeneration of the tissue since it acts a matrix for the migration of cells. The PRF also promotes revascularization of teeth due to the release of growth factors (Chowdhury et al. 2013).

The three criteria for the success of any regenerative procedures, including regenerative endodontics, are stem cells, signaling molecules, and an ideal scaffold. From a study conducted by the Huang et al, it was found that there was proliferation of the human dental pulp cells and increased protein expression of osteoprogenin and alkaline phosphatase activity in cases where PRF was used. Once the inflammation subsided, the dental pulp cells differentiate into odontoblast-like cells under the influence of Hertwig's epithelial root sheath. It was reported that revitalization of a necrotic infected immature tooth was possible when PRF was used as a biomaterial for pulp dentin complex regeneration under conditions of total canal disinfection (Shivashankar et al. 2012)

Cysts, associated with these endodontic lesions or present independently, can be treated using a mixture of bone grafts and PRF as it helps in the faster filling of the deficiencies with bone tissue and also faster gingival regeneration. The PRF can be used as a membrane to repair the grafted area in cases where the gingival wound closure is impossible (Shivashankar et al. 2013, Yan et al. 2006). This material along with Biodentine has been used in the successful treatment of cases wherein the anatomic defectpalatogingival groove of the lateral incisor had caused a periodontal pocked (approx. 9mm) and had caused the necrosis of the pulp (Johns et al. 2014).

4) In the new and ever developing field of implantology, such as reconstructive implant surgery, socket preservation, treatment of fenestration defects around implants, when it comes to implanting placement, uneventful extraction is of utmost importance along with bone regeneration around the implant site and improved healing of the gingiva for the success of an implant. In such cases, PRF due to its simple, inexpensive and less time-consuming preparation is considered an ideal material to be used as plugs for filling of avulsion sockets even under conditions of severe socket destructions due to cysts. It can also be used along with bone substitutes, and can be used as a protective biological barrier membrane, thus promoting gingival healing in cases where gingival wound closure is difficult to attain even with sutures. It was also found to reduce the risk of flap necrosis by stimulating angiogenesis and promote the impregnation of the surgical site with blood proteins, followed by cell induction pertaining to slow release of the growth factors and cytokines. In addition, the material was seen to promote tissue remodeling in such a way that the time required for healing and wound closure is minimized along with reduced post-surgical pain and edema (Choukroun et al. 2006).

Mazor (2009) assessed the relevance of autologous leukocyte-, and platelet-rich fibrin (PRF) concentrate and membranes as the sole filling material during a lateral sinus lift with immediate implantation in a case series. From a radiologic and histologic point of view at six months after surgery, the use of PRF as the sole filling material during a simultaneous sinus lift and implantation brought about a high volume of naturally regenerated bone in the sub sinus cavity up to the tip of the implants. Further, they advocated that Choukroun's PRF is a simple and inexpensive biomaterial, and its systematic use during a sinus lift seems a relevant option.

5) In post-surgical procedures to complement healing of donor site, PRF membrane, which is obtained after compression of $\mathrm{PRF}$, can be used to reduce the healing time of the donor site. The PRF membrane provides a solid, stable fibrin mesh which is more rigid than the blood clot. The presence of growth factors such as PDGFs and TGFs accelerates the proliferation and migration of fibroblasts inside the wound (Albanese et al. 2013)

\section{Conclusion}

Platelet concentrates as a whole have shown to have great scope in the field of reconstructive and regenerative medicine and dentistry. And PRF being the more recent of the Platelet Derivatives is safer and simpler than the previous PRP concentrates hence they are easily used clinically. The healing and regenerative properties of the PRF are attributed to its basic fibrin composition. This autologous fibrin matrix has the ability to release cytokines over a period of 7-11 days along with the slower release of growth factors, which helps in reducing the healing time. The threedimensional architecture of the fibrin matrix also helps in better wound healing by an efficient direct stem cell migration. Also the elastic nature of the fibrin matrix allows the clinician to manipulate the material according to the use. It also helps in reducing the shrinkage and necrosis of flap, maintenance of the flap in a stable position and wound coverage owing to the mechanical adhesive property of the fibrin matrix. PRF was found to accelerate endothelial, epithelial and endodermal regeneration along with neoangiogenesis and enhanced collagen synthesis. In dentistry, they have been used most in conjuncture with membranes and grafts in cases relating to sinus augmentation, implants placement and endo-perio lesions (including intra-bony defects, gingival recession) and alveolar bone loss to increase the rate of healing and repair owing to the release of various growth factors such as PDGF and TGF. The property of PRF as an ideal scaffold material finds its use in endodontic treatment of necrotic tooth by regeneration of dental pulp cells.

\section{References}

[1] Albrektsson T, Bach A, Edshage S \&Jonsson A (1982): Fibrin adhesive system influence on Bone healing rate. A microradiographical evaluation.ActaOrthopScand53, 757-763. 
[2] Albanese A, Licata ME, Polizzi B \&Campisi G (2013): Platelet-rich plasma (PRP) in dental and oral surgery: from the wound healing to bone regeneration. Immun\&Ageing, 10:23. http://dx.doi.org/10.1186/1742-4933-10-23.

[3] Bianco P\& Robey PG (2001): Stem cells in tissue engineering.Nature 414, 118-121. http://dx.doi.org/10.1038/35102181.

[4] Burnouf T, Radosevich M \&Goubran H (2008): Local hemostatic blood products in hemophilia care: fibrin sealant and platelet gel. In: Monograph, World Federation of Hemophilia. World Federation of Hemophilia, Montreal, 1-14.

[5] Choukroun J, Diss A, Simonpieri A, Girard MO, SchoefflerC, Dohan SL, Dohan AJ, Mouhyi J \& Dohan DM (2006): Platelet-rich fibrin (PRF): a second-generation platelet concentrate. Part I: Technologica concepts and evolution. Oral Surg Oral Med Oral Pathol Oral Radi olEndod 101 ,

e37-e44 http://dx.doi.org/10.1016/j.tripleo.2005.07.012.

[6] Choukroun J, Diss A, Simonpieri A, Girard MO, SchoefflerC, Dohan SL, Dohan AJ, Mouhyi J \& Dohan DM (2006): Platelet-rich fibrin (PRF): a second-generation platelet concentrate.Part II: Plateletrelated biologic features. Oral Surg Oral Med Oral Pathol Oral RadiolEndod 101 ,

e45-e50. http://dx.doi.org/10.1016/j.tripleo.2005.07.012.

[7] Choukroun J, Diss A, Simonpieri A, Girard MO, Schoeffler C, Dohan SL, Dohan AJ, Mouhyi J \&Dohan DM (2006): Platelet-rich fibrin (PRF): a second-generation platelet concentrate.Part IV: Clinical effects on tissue healing. Oral Surg Oral Med OralPathol Oral RadiolEndod 101 , http://dx.doi.org/10.1016/j.tripleo.2005.07.012

[8] Choukroun J, Diss A, Simonpieri A, Girard MO, SchoefflerC, Dohan SL, Dohan AJ, Mouhyi J \& Dohan DM (2006): Platelet-rich fibrin (PRF): a second-generation platelet concentrate. Part V: histologic evaluations of PRF effects on bone allograft maturation in sinus lift. Oral Surg Oral Med OralPathol Oral RadiolEndod101, 299-303. http://dx.doi.org/10.1016/j.tripleo.2005.07.012.

[9] Chowdhury S, Gokkulakrishnan S \& K.Y Giri (2013): Use of Choukroun's Platelet Rich Fibrin in Oral Defects. Jdent Scioral rehabil JanMarch, $16-20$.

[10]Ehrenfest DM, de Peppo GM, Doglioli P \&Sammartino G (2009): Slow release of growth factors and thrombospondin-1 in Choukroun's platelet-rich fibrin (PRF): A gold standard to achieve for all surgical platelet concentrates technologies. Growth Factors 27, 63-69. http://dx.doi.org/10.1080/08977190802636713.

[11]Ehrenfest DM (2010): How to optimize the preparation of leukocyteand platelet-rich fibrin (L-PRF, Choukroun's technique) clots and membranes: Introducing the PRF Box. Oral Surg Oral Med Oral Pathol Oral RadiolEndod 110(3), 275-278. http://dx.doi.org/10.1016/i.tripleo.2010.05.048.

[12]Ehrenfest DM, Del Corso M, Diss A, Mouhyi J \& Charrier JB (2010): Three-dimensional architecture and cell composition of a Choukroun's platelet-rich fibrin clot and membrane. J PeriodontolApr 81 546-55. http://dx.doi.org/10.1902/jop.2009.090531.

[13]Ehrenfest DM, Bielecki T, Jimbo R, Barbe G, Del Corso M, Inch ingolo F \&Sammartino G (2012): Do the Fibrin Architecture and Leukocyte Content Influence the Growth Factor Release of Platelet Concentrates? An Evidence-based Answer Comparing a Pure PlateletRich Plasma (P-PRP) Gel and a Leukocyte- and Platelet-Rich Fibrin (L-PRF).Curr Pharm Biotechnol Jun 13(7), 1145-1152 http://dx.doi.org/10.2174/138920112800624382.

[14]Ehrenfest DM, Andia I, Zumstein MA, Zhang CQ, Pinto NR \&Bielecki T (2014): Classification of platelet concentrates (PlateletRich Plasma-PRP, Platelet-Rich Fibrin-PRF) for topical and infiltrative use in orthopedic and sports medicine: current consensus, clinical implications and perspectives. Muscles, ligaments and tendons J.4, 3-

[15] Giannobile WV, Hernandez RA, Finkelman RD, Ryarr S, Kiritsy CP D'Andrea M \& Lynch SE(1996): Comparative effects of plateletderived growth factor-BB and insulin-like growth factor-I, individually and in combination, on periodontal regeneration in Macacafascicularis. $J$ Periodontal Res 31, 301-312. http://dx.doi.org/10.1111/j.1600-0765.1996.tb00497.x.

[16] He L, Lin Y, Hu X, Zhang Y \&Wu H (2009): A comparative study of platelet-rich fibrin (PRF) and platelet-rich plasma (PRP) on the effect of proliferation and differentiation of rat osteoblasts in vitro. Ora Surg Oral Med Oral Pathol Oral RadiolEndod 108, 707-713. http://dx.doi.org/10.1016/j.tripleo.2009.06.044.

[17] Inchingolo F1, Tatullo M, Marrelli M, Inchingolo AM, Scacco S, Inchingolo AD, Dipalma G, Vermesan D, Abbinante A \&Cagiano R (2010): Trial with Platelet-Rich Fibrin and Bio-Oss used as grafting materials in the treatment of the severe maxillar bone atrophy: clinical and radiological evaluations.Eur Rev Med PharmacolSci Dec 14 1075-84.

[18]Johns DA, Shivashankar VY, Shobha K \&Johns M (2014): An innovative approach in the management of palatogingival groove using BiodentineTM and platelet-rich fibrin membrane. J Conserv Dent JCD $\quad 17, \quad 75-79 . \quad$ doi:10.4103/0972-0707.124156. http://dx.doi.org/10.4103/0972-0707.124156.

[19] Kobayashi M1, Kawase T, Horimizu M, Okuda K, Wolff LF \&Yoshie $H$ (2012): A proposed protocol for the standardized preparation of PRF membranes for clinical use. Biologicals Sep 40, 323-9. doi: 10.1016/j.biologicals.2012.07.004. Epub 2012 Jul 28. http://dx.doi.org/10.1016/j.biologicals.2012.07.004.

[20]Khiste\&Tari (2013): Platelet-Rich Fibrin as a Biofuel for Tissue Regeneration. ISRN Biomaterials Article ID 627367. doi:10.5402/2013/627367. http://dx.doi.org/10.5402/2013/627367.

[21]Lucarelli E, Beccheroni A, Donati D, Sangiorgi L, Cenacchi A, Del Vento AM, Meotti C, Bertoja AZ, Giardino R, Fornasari PM, Mercuri M \&Picci P (2003):Platelet-derived growth factors enhance proliferation of human stromal stem cells. Biomaterials 24, 3095-3100. http://dx.doi.org/10.1016/S0142-9612(03)00114-5.

[22]L. Le Guéhennec, P Layrolle\& G Daculsi (2004): A review of bioceramics and fibrin sealant. Eur Cell Mater 8, 1-10.

[23]Marx ER (1999): Platelet-rich plasma: A source of multiple autologous growth factors for bone grafts. In: Lynch SE, Genco RJ, Marx $R E$, editors. Tissue engineering, applications in maxillofacial surgery and periodontics, Quintessence Publishing Co, Inc Illinois, 71-82.

[24]Mazor Z, Horowitz RA, Del Corso M, Prasad HS, Rohrer MD \& DohanEhrenfest DM (2009): Sinus floor augmentation with simultaneous implant placement using Choukroun'splateletrich fibrin as the sole grafting material: a radiologic and histologic study at 6 months. $J$ Periodontol 80, 2056-64. http://dx.doi.org/10.1902/jop.2009.090252.

[25]Patel JS, Patel SG \&Kadam C (2013):Choukroun's platelet rich fibrin in regenerative dentistry. Univ Res $J$ Dent 3, 22-25. http://dx.doi.org/10.4103/2249-9725.119046.

[26]Qi Li, Pan S, Dangaria, Smit J , Gopinathan, Gokul, Kolokythas, Antonia, Chu S, Geng Y, Zhou Y \&Luan X,Platelet-Rich Fibrin Promotes Periodontal Regeneration and Enhances Alveolar Bone Augmentation. BioMed Research International Article ID 63804313 pages. doi:10.1155/2013/638043. http://dx.doi.org/10.1155/2013/638043.

[27]Raja \& Naidu (2008): Platelet-rich fibrin: evolution of a secondgeneration platelet concentrate. Indian $J$ Dent 19, 42-46. http://dx.doi.org/10.4103/0970-9290.38931.

[28] Simonpieri A, Del Corso M, Vervelle A, Jimbo R, Inchingolo F, Sammartino G \&Dohan Ehrenfest DM (2012): Current knowledge and perspectives for the use of platelet-rich plasma (PRP) and platelet-rich fibrin (PRF) in oral and maxillofacial surgery part 2: Bone graft, implant and reconstructive surgery. Curr Pharm Biotechnol Jun 13, 1231-56. http://dx.doi.org/10.2174/138920112800624472.

[29]Shivashankar V Y, Johns DA, Vidyanath S \&Ramesh Kumar M (2012): Platelet Rich Fibrin in the revitalization of tooth with necrotic pulp and open apex. J Conserv Dent. 15(4), 395-398. doi: 10.4103/0972-0707.101926 http://dx.doi.org/10.4103/09720707.101926 .

[30] Shivashankar VY, Johns DA, Vidyanath S \&Sam G (2013): Combination of platelet rich fibrin, hydroxyapatite and PRF membrane in the management of large inflammatory periapical lesion. $J$ ConservDent 16, 261-4. http://dx.doi.org/10.4103/0972-0707.111329.

[31]Toffler M, ToscanoN, Holtzclaw D, Corso MD \&Ehrenfest DD (2006): Introducing Choukroun's Platelet Rich Fibrin (PRF) to the Reconstructive Surgery Milieu. J Imp AdvClinDent 1, 21 -31.

[32] Yan MT (2006): The management of periapical lesions in endodonticallytreated teeth. AustEndodJ 32, 2-15. doi: 10.1111/j.17474477.2006.00002.x 4477.2006.00002.x.

[33]Zaky SH, CanceddaR (2009): Engineering craniofacial structures: facing the challenge. $J$ Dent Res 88, 1077-1091. http://dx.doi.org/10.1177/0022034509349926. 